\title{
Vascular endothelial growth factor expression in metastatic pulmonary tumor from colorectal carcinoma: Utility as a prognostic factor
}

\author{
Masaya Tamura, MD \\ Makoto Oda, MD \\ Yoshio Tsunezuka, MD \\ Isao Matsumoto, MD \\ Kazuyuki Kawakami, MD \\ Go Watanabe, MD
}

From the Department of General and Cardiothoracic Surgery, Kanazawa University School of Medicine, Kanazawa, Japan.

Received for publication Oct 2, 2003; revisions received Feb 16, 2004; accepted for publication March 1, 2004.

Address for reprints: Masaya Tamura, MD, Department of General and Cardiothoracic Surgery, Kanazawa University School of Medicine, Takara-machi 13-1, Kanazawa 920-8640, Japan (E-mail: m-tamura@sf.m. kanazawa-u.ac.jp).

J Thorac Cardiovasc Surg 2004;128:517-22 $0022-5223 / \$ 30.00$

Copyright $\odot 2004$ by The American Association for Thoracic Surgery

doi:10.1016/j.jtcvs.2004.03.056
Objective: To define the most reliable prognostic factor, we studied the 5-year survival of patients after resection of pulmonary metastases from colorectal cancer in relation to various prognostic factors, including vascular endothelial growth factor expression in primary and metastatic tumors.

Methods: A retrospective study was undertaken in 49 patients who had undergone complete resection of pulmonary metastasis from colorectal carcinoma. All patients were retrospectively analyzed for sex, age, location and stage of primary tumor, number of pulmonary metastases, type of pulmonary resection, size of metastatic tumor, lymph node metastasis, and prethoracotomy carcinoembryonic antigen level. Furthermore, vascular endothelial growth factor expression of both primary and metastatic tumors was investigated.

Results: Overall 5-year survival was $34.3 \%$. In the univariate analysis the number of pulmonary metastases $(P=.007)$ and vascular endothelial growth factor expression in metastatic tumors $(P=.008)$ and primary colorectal tumors $(P=.011)$ were significantly associated with poor survival. In the multivariate analysis the number of pulmonary metastases $(P=.0031)$, vascular endothelial growth factor expression in metastatic tumors $(P=.0057)$, and stage of primary tumor $(P=.0321)$ were characteristics that retained a significant independent prognostic effect on overall survival. A statistically significant difference was not found in the 5-year survival of patients with solitary and negative vascular endothelial growth factor expression in metastatic tumors $(59.1 \%)$ versus those with multiple and positive vascular endothelial growth factor expression in metastatic tumors $(10.0 \% ; P \leq .0001)$.

Conclusions: Vascular endothelial growth factor expression in metastatic pulmonary tumors is an important prognostic marker for patients with pulmonary metastasis from colorectal carcinoma. Our results suggested that patients with multiple and positive vascular endothelial growth factor expression in the metastatic tumor will not receive benefit from metastasectomy.

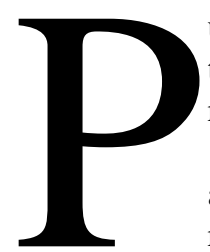

ulmonary metastasis is the most common extra-abdominal manifestation of advanced colorectal cancer. Blalock ${ }^{1}$ first reported a surgical resection for pulmonary metastasis from colorectal carcinoma in 1944. To date, there is no effective chemotherapeutic treatment available for metastatic colorectal cancer. Thus far, surgical intervention remains the only effective treatment for patients with limited metastatic disease. Several prognostic factors affecting survival after a resection of pulmonary metastasis from colorectal carcinoma have been suggested. However, 
TABLE 1. The characteristics of 49 patients undergoing resection of pulmonary metastasis from colorectal cancer

No. of patients

\begin{tabular}{lc} 
Sex & \\
Male & 35 \\
Female & 14 \\
Age (y) & \\
$\quad$ Average & 62.9 \\
Range & $43-79$ \\
Location of primary cancer & \\
Colon & 26 \\
Rectum & 23 \\
Stage of primary cancer & \\
Dukes A & 9 \\
Dukes B & 14 \\
Dukes C & 26 \\
No. of pulmonary metastases & \\
Solitary & 26 \\
Multiple & 23 \\
No. of resections & \\
1 & 40 \\
P2 & 9 \\
Site of pulmonary metastasis & \\
Unilateral & 7 \\
Bilateral & 42 \\
Type of pulmonary resection & \\
Wedge resection & 28 \\
Segmentectomy & 12 \\
Lobectomy & 1 \\
Pneumonectomy & \\
\hline
\end{tabular}

contradicting results have been reported regarding various prognostic factors, and controversy remains over which factors are the best indicators for surgical resection. To better define the reliability of prognostic factors, we studied the 5-year survival of patients after resection of pulmonary metastasis from colorectal cancer in relation to various prognostic factors, including vascular endothelial growth factor (VEGF) expression in primary and metastatic tumors.

\section{Patients and Methods}

Forty-nine patients (35 male and 14 female patients) underwent pulmonary resection of metastasis lesions from colorectal cancer between April 1984 and March 2001 in our institute. There were no hospital deaths within 30 days after thoracotomy. In all patients, metastasectomy was performed after confirming that the metastatic site was confined to the lung. The extrathoracic metastasis was ruled out preoperatively by means of brain magnetic resonance imaging, radionuclide bone scanning, and abdominal computed tomography. A barium enema or colonofiberoscopy was used to confirm that the primary site was not recurrent. Complete resection of the pulmonary metastasis was performed in all cases. Although wedge resection for the pulmonary metastatic tumor was performed in principle, lobectomy or pneumonectomy was performed, taking the size and position of the tumors into account. Histologic proof of diagnosis was available from all resected lung lesions. Lymph node biopsy was performed when the metastasis was suspected preoperatively or intraoperatively. Nineteen patients had received their colorectal operations at other hospitals. Staging of the primary colon lesion was confirmed through a review of the surgical and pathologic records. Patient records were reviewed for sex, age, location and stage of primary tumor, number of pulmonary metastases, type of pulmonary resection, size of metastatic tumor, lymph node metastasis, and prethoracotomy carcinoembryonic antigen (CEA) level. Furthermore, VEGF expression of both primary and metastatic tumors was investigated.

Table 1 summarizes the characteristics of the 49 patients. Patient age ranged from 43 to 79 years, with an average of 62.9 years. The primary lesion was located on the colon in 26 patients and on the rectum in 23 patients. The distribution of Dukes' stage of primary colorectal cancer is given in Table 1. Twenty-six patients had a solitary metastasis, and 23 had multiple metastases. Nine patients underwent pulmonary metastasis resection more than twice. Seven patients underwent bilateral pulmonary resection. A wedge resection was performed in 28 patients, segmentectomy in 8 patients, lobectomy in 12 patients, and pneumonectomy in 1 patient. In 15 patients the nodal status could not be determined. Sampling of lymph nodes was performed in 34 patients. Thirteen patients had hilar or mediastinal lymph node metastasis.

The expression of VEGF in cancer cells at the primary site and metastatic tumors was also immunohistochemically assessed by using the labeled streptavidin-biotin method, as described previously. ${ }^{2,3}$ For the primary antibody, we used the anti-VEGF polyclonal antibody (Santa Cruz Biotechnology Inc, Heidelberg, Germany) diluted 100-fold. Paraffin-embedded sections of the invasive edges of the tumors were reacted with the antibody for 2 hours at room temperature. The second antibody used was biotinlabeled goat anti-mouse immunoglobulin (DAKO). The immunoreactivities for VEGF were graded as $(-),(+)$, and $(++)$ according to the staining intensity of the tumor cells: $(-)$ represents $0 \%$ or less than $10 \%$ positive staining area, $(+)$ represents $10 \%$ to $50 \%$ positive staining area, and $(++)$ represents more than $50 \%$ positive staining area. In this study we defined a tumor with the strongest stain $(++)$ as positive VEGF expression. ${ }^{2}$ Positivity was evaluated by 2 independent observers without knowledge of the clinicopathologic factors. The mean follow-up period was $102 \pm$ 45 months.

The survival was calculated from the date of the pulmonary resection according to the Kaplan-Meier method. The influence of variables on survival was analyzed by using the log-rank test for discrete variables and the Cox proportional hazards model for continuous variables.

\section{Results}

The overall cumulative 5-year survival was $34.3 \%$. The 5-year survival was $46.3 \%$ for patients with a solitary metastasis $(\mathrm{n}=26)$ compared with $18.2 \%$ for those with 2 or more metastases $(\mathrm{n}=23 ; P=.006$; Figure 1$)$. The 5-year survival for the 19 patients with a prethoracotomy CEA level of less than $2 \mathrm{ng} / \mathrm{mL}$ was $48.3 \%$ compared with $25.7 \%$ for the 30 patients with a CEA level of $2 \mathrm{ng} / \mathrm{mL}$ or greater $(P=.061)$. The 5-year survival for patients with a lymph node metastasis was $38.5 \%$ compared with $23.1 \%$ for those without a lymph node metastasis. There was no statistically 


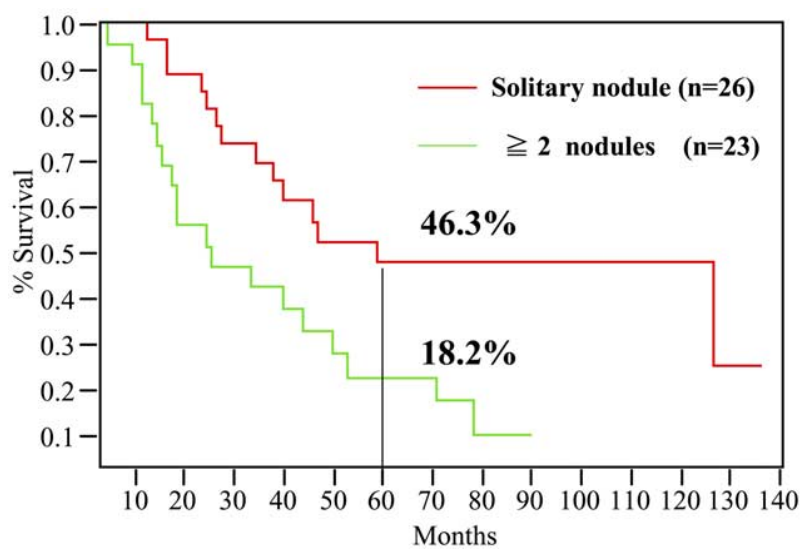

Figure 1. Patient survival by number of metastatic lesions. The cumulative survival for 26 patients with a solitary pulmonary metastasis was $46.3 \%$ at 5 years, whereas that for 23 patients with 2 or more pulmonary metastases was $18.2 \%(P=.006)$.

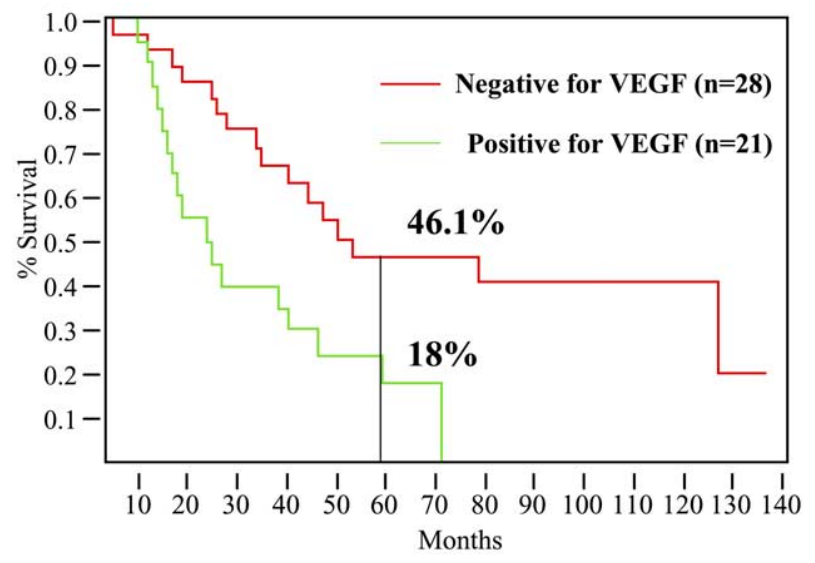

Figure 2. Survival curves by VEGF expression in metastatic tumors. The prognosis for patients with positive VEGF expression in a metastatic tumor was significantly low $(P=.0046)$.

significant difference between the 2 groups $(P=.216)$. The association of other prognostic variables, such as the number of resections and the site of pulmonary metastasis, revealed no significant difference in survival $(P=.346$ and $P=.248$, respectively). The VEGF expression in metastatic tumor significantly influenced survival $(P=.0046)$. The 5 -year survival was $46.1 \%$ for patients with negative VEGF expression in the metastatic tumor versus $18.0 \%$ for patients with positive VEGF expression (Figure 2).

The univariate analysis revealed that stage of primary tumor $(P=.028)$, number of pulmonary metastases $(P=$ $.007)$, prethoracotomy CEA level $(P=.059)$, VEGF expression in metastatic tumor $(P=.008)$, and VEGF expression in primary tumor $(P=.011)$ were significantly associated with poor survival (Table 2). The multivariate

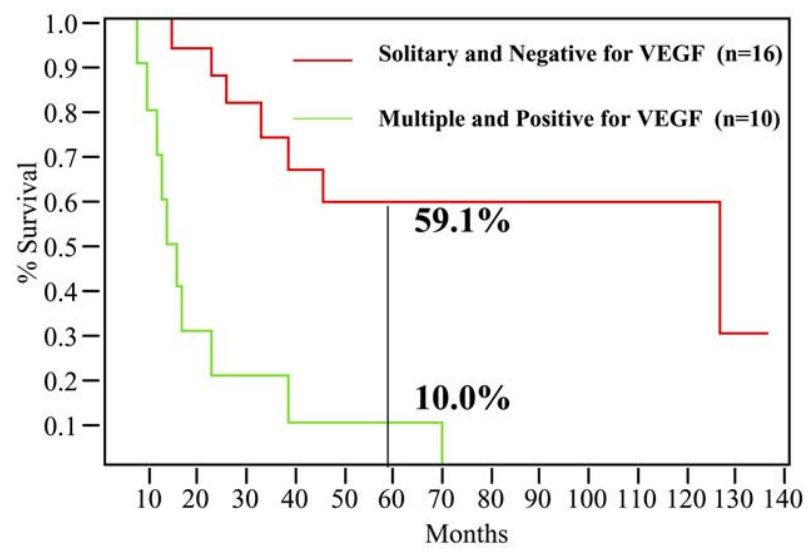

Figure 3. Survival curves in relation to the number of metastases and VEGF expression in metastatic tumors. The cumulative survival for 16 patients with a solitary metastasis with negative VEGF expression was $59.1 \%$ at 5 years, whereas that for 10 patients with multiple metastases with positive VEGF expression was 10.0\% $(P \leq .0001)$.

TABLE 2. Prognostic effect of clinicopathologic and biologic factors on survival (univariate analysis)

\begin{tabular}{|c|c|c|c|}
\hline Factors & $P$ value & Hazard ratio & $95 \% \mathrm{CI}$ \\
\hline Age, y $(\geq 66$ vs $<66)$ & .9 & 1.05 & $0.50-2.10$ \\
\hline Sex (male vs female) & .88 & 1.06 & $0.47-2.23$ \\
\hline $\begin{array}{l}\text { Primary site (colon vs } \\
\text { rectum) }\end{array}$ & .96 & 0.98 & $0.49-2.01$ \\
\hline $\begin{array}{l}\text { Stage of primary cancer } \\
\text { (Dukes A, B vs Dukes C) }\end{array}$ & .028 & 1.98 & $0.95-4.15$ \\
\hline $\begin{array}{l}\text { No. of pulmonary } \\
\text { metastases (solitary vs } \\
\text { multiple) }\end{array}$ & .0067 & 2.82 & $1.38-5.70$ \\
\hline $\begin{array}{l}\text { Type of pulmonary resection } \\
\text { (partial vs other) }\end{array}$ & .5 & 1.15 & $0.75-1.70$ \\
\hline $\begin{array}{l}\text { CEA level, ng/mL ( } \geqq 2.0 \text { vs } \\
\quad<2.0 \text { ) }\end{array}$ & .059 & 1.92 & $0.97-4.26$ \\
\hline $\begin{array}{l}\text { Metastatic tumor size, } \mathrm{mm} \\
(\geqq 30 \text { vs }<30)\end{array}$ & .83 & 0.93 & $0.45-1.86$ \\
\hline $\begin{array}{l}\text { Disease-free interval, y ( } \geqq 2 \\
\quad \text { vs }<2 \text { ) }\end{array}$ & .79 & 0.92 & $0.52-1.71$ \\
\hline $\begin{array}{l}\text { VEGF (metastatic site) } \\
\text { (positive vs negative) }\end{array}$ & .0078 & 2.71 & $1.32-5.64$ \\
\hline $\begin{array}{l}\text { VEGF (primary site) (positive } \\
\text { vs negative) }\end{array}$ & .011 & 2.17 & $1.14-12.3$ \\
\hline
\end{tabular}

$\mathrm{Cl}$, Confidence interval; $C E A$, carcinoembryonic antigen; VEGF, vascular endothelial growth factor.

analysis revealed that number of pulmonary metastases $(P$ $=.0031)$, VEGF expression in metastatic tumor $(P=$ $.0057)$, and stage of primary tumor $(P=.0321)$ were characteristics that retained a significant independent prognostic effect on overall survival (Table 3). A statistically significant difference $(P \leq .0001)$ was found in the 5 -year 
TABLE 3. Multivariate analysis by means of Cox proportional hazard regression model

\begin{tabular}{|c|c|c|c|c|}
\hline \multirow[b]{2}{*}{ Factors } & \multicolumn{2}{|c|}{ Characteristics } & \multirow[b]{2}{*}{$P$ value } & \multirow[b]{2}{*}{ Hazard ratio $(95 \% \mathrm{CI})$} \\
\hline & Unfavorable & Favorable & & \\
\hline No. of pulmonary metastases & Multiple & Solitary & .0031 & $3.20(1.48-7.20)$ \\
\hline VEGF (metastatic site) & Positive & Negative & .0057 & $3.20(1.41-7.29)$ \\
\hline Stage of primary cancer & Dukes C & Dukes $A, B$ & .0321 & $1.69(1.09-2.91)$ \\
\hline CEA level & $\geqq 2.0 \mathrm{ng} / \mathrm{mL}$ & $<2.0 \mathrm{ng} / \mathrm{mL}$ & .1015 & $1.46(0.61-3.69)$ \\
\hline
\end{tabular}

$C l$, Confidence interval; VEGF, vascular endothelial growth factor; $C E A$, carcinoembryonic antigen.

survival of patients with solitary and negative VEGF expression in the metastatic tumor $(n=16)$ versus those with multiple and positive VEGF expressions in the metastatic tumor $(\mathrm{n}=10 ; 59.1 \%$ and $10.0 \%$, respectively; Figure 3$)$.

\section{Discussion}

Pulmonary metastases from colorectal carcinoma in most patients are multiple and a subsequent expression of generalized metastatic disease. ${ }^{4,5}$ There still exists a subgroup of patients in whom the only site of recurrence is the lung. ${ }^{4}$ In this study patients with pulmonary metastases from colorectal carcinoma underwent surgical intervention after confirming that no other recurrence had existed, including at the primary site. Several studies concerning operations for pulmonary metastasis from colorectal carcinoma have been published, and the 5-year survivals reported ranged from $9 \%$ to $42 \% .^{6-12}$ In this study all patients underwent complete resection of all pulmonary metastases, and the overall 5-year survival was $34.3 \%$.

A number of prognostic factors affecting survival after a resection of pulmonary metastasis from colorectal carcinomas have been reported in other series (Table 4). ${ }^{6-13}$ However, the survival in relation to the prognostic factors varied among the institutions, and it remains unclear as to which factors are the best indicators for surgical resection. The number of metastases was a significant prognostic factor in most studies. ${ }^{6-11,13}$ On the other hand, Inoue and colleagues ${ }^{12}$ reported that there was no significant difference in survival between patients with solitary and multiple lesions and asserted that most of these analyses included cases involving incompletely resected multiple metastases. It is possible that the more pulmonary metastasis that exists at the time of resection, the more likely that micrometastases are latent in the lung. In our study we observed a significant association between the number of pulmonary metastases and postthoracotomy survival. The multivariate analysis revealed that the number of metastases was a characteristic that retained a significant independent prognostic effect on overall survival $(P=.0031)$. In the presented study more than 4 tumors were resected in 13 patients.

Recently, several reports have revealed that the prognosis of patients with increased prethoracotomy serum CEA levels was poor. ${ }^{10,12,13}$ In our study the patients with normal prethoracotomy serum CEA levels who underwent pulmonary metastasectomies had a significantly higher 5-year survival than those with high serum CEA levels $(48.3 \%$ vs $25.7 \%$ ), but CEA was not an independent prognostic factor according to the multivariate analysis. In this study the presence of lymph node metastasis did not seem to affect the patients' prognoses. This result might have been influenced by the fact that lymph node dissection or sampling was not performed in some of the patients (15 of 49). Inoue and colleagues ${ }^{12}$ reported that hilar or mediastinal lymph node metastasis influences the postthoracotomy survival. They had examined the presence of lymph node metastasis in all of the patients to clarify the incidence of lymph node involvement. Pfannschmidt and associates ${ }^{13}$ reported that thoracic lymph node metastasis was identified as a prognostic-related criteria for surgical intervention, and pulmonary resection of a single nodule without systematic lymph node dissection is not recommended.

Tumor angiogenesis is a fundamental step in the growth and progression of solid tumors and also an important step of the complex metastatic system. ${ }^{14}$ VEGF is associated with tumor progression through various biologic functions, such as immune reactions mediated by the maturation of dendritic cells, migration of tumor cells, malignant transformation and invasion, tumor survivability, and tumor angiogenesis. ${ }^{15-20}$ To our knowledge, no studies have addressed the clinical significance of VEGF expression of metastatic lung tumor. In this study we investigated the expression of VEGF in both primary colorectal tumors and metastatic lung tumors. Furthermore, we investigated whether VEGF expression in the tumor is a prognostic factor. In most cases VEGF expression was positive in primary colorectal tumors, whereas its expression was negative in the metastatic tumors. Twenty of 38 cases revealed negative VEGF expression in the metastatic pulmonary tumor, although results were positive in primary colorectal tumors. The characteristics of metastatic lung tumors are sometimes different from those of primary colorectal cancer. The decreased expression of VEGF might indicate that the tumor growth is in a dormant state. The multivariate analysis revealed that the number of pulmonary metastases and VEGF expression in metastatic tumors were characteristics that retained a significant independent prognostic ef- 
TABLE 4. Review of the prognostic factors for resectable pulmonary metastasis from colorectal carcinoma

\begin{tabular}{|c|c|c|c|c|c|c|c|c|c|c|}
\hline \multirow[b]{2}{*}{ Author and reference no. } & \multirow[b]{2}{*}{$\begin{array}{c}\text { Published } \\
\text { year }\end{array}$} & \multirow[b]{2}{*}{ n } & \multirow[b]{2}{*}{$\begin{array}{c}\text { 5-y } \\
\text { survival } \\
(\%)\end{array}$} & \multicolumn{7}{|c|}{ Prognostic factors } \\
\hline & & & & $\begin{array}{c}\text { No. of } \\
\text { metastases }\end{array}$ & $\begin{array}{c}\text { Size of } \\
\text { metastases }\end{array}$ & DFI & $\begin{array}{c}\text { Stage of } \\
\text { primary cancer }\end{array}$ & $\begin{array}{l}\text { Type of } \\
\text { pulmonary } \\
\text { resection }\end{array}$ & $\begin{array}{c}\text { Prethoracotomy } \\
\text { CEA }\end{array}$ & $\begin{array}{c}\text { LN } \\
\text { metastasis }\end{array}$ \\
\hline Wilking and coworkers 6 & 1985 & 27 & 9 & + & * & * & * & * & * & $*$ \\
\hline Mansel and coworkers ${ }^{7}$ & 1986 & 66 & 38 & + & - & - & - & - & * & * \\
\hline Brister and coworkers ${ }^{8}$ & 1988 & 27 & 21 & $*$ & * & + & - & * & * & * \\
\hline Goya and coworkers ${ }^{9}$ & 1989 & 65 & 42 & + & + & - & - & * & $*$ & * \\
\hline $\begin{array}{l}\text { McAfee and } \\
\text { coworkers }^{10}\end{array}$ & 1992 & 139 & 30.5 & + & - & * & * & * & + & * \\
\hline Yano and coworkers ${ }^{11}$ & 1993 & 27 & 41.1 & + & - & - & - & - & * & * \\
\hline Inoue and coworkers ${ }^{12}$ & 2000 & 25 & 39.2 & - & - & - & * & * & + & + \\
\hline $\begin{array}{l}\text { Pfannschmidt and } \\
\text { coworkers }^{13}\end{array}$ & 2003 & 167 & 32.4 & + & * & - & * & * & + & + \\
\hline Our report & 2003 & 49 & 34.3 & + & - & - & + & - & + & - \\
\hline
\end{tabular}

$D F I$, Disease-free interval; $C E A$, carcinoembryonic antigen; $L N$, lymph node; ${ }^{*}$, not investigated; + , significant prognostic factor; - , not prognostic factor.

fect on overall survival. A better 5-year survival was observed in patients with single and negative VEGF expressions in the metastatic tumor $(59.1 \%)$. On the contrary, patients with multiple metastases with positive VEGF expression showed poor 5-year survivals (10.0\%). Such results indicates that it might be possible to select efficiently the patients who are candidates for metastasectomy by taking into consideration both the number of metastases and the level of VEGF expression in the metastatic tumor. For the treatment of patients with multiple pulmonary metastases from colorectal cancer, open excisional biopsy should be performed for one of the tumors, and VEGF expression should be examined. Two-staged operation is desirable for the cases that reveal negative VEGF expression in the metastatic tumor. If the tumor reveals positive VEGF expression, further treatment should be carefully planned to avoid unnecessary operations. By using videoassisted thoracic surgery, not only can tumor biopsy be performed less invasively, but also cases that will not receive benefit from surgical treatment can be ruled out. Needle biopsy of excisional biopsy of the tumor should be performed for patients with multiple metastases from colorectal cancer, and the VEGF expression should be examined.

It is desirable to evaluate the VEGF expression in the metastatic tumor preoperatively. In this study VEGF expression was evaluated by using paraffin-embedded tumor sections. We reported that there was a significant correlation between circulating VEGF levels and intratumoral VEGF levels in patients with primary non-small cell lung cancer. ${ }^{21}$ Werther and coworkers ${ }^{22}$ analyzed the prognostic value of matched preoperative serum and plasma VEGF concentrations in patients with colorectal cancer. This study indicated that preoperative serum VEGF expression is a better predictor of overall survival than plasma VEGF expression, but in comparison with other prognostic factors, the reliability of serum VEGF expression is not yet proved. Further pro- spective study is required to investigate whether circulating VEGF levels reflect the VEGF expression in the metastatic tumor and can be regarded as a prognostic marker for patients with pulmonary metastases from colorectal cancer.

In conclusion, the number of pulmonary metastatic tumors and positive VEGF expression in metastatic tumor are the most reliable factors that determine long-term survival of the patients with resectable pulmonary metastasis from colorectal carcinoma. Our results suggested that patients with multiple and positive VEGF expression in the metastatic tumor will not receive benefits from metastasectomy.

\section{References}

1. Blalock A. Recent advances in surgery. N Engl J Med. 1944;231: $267-7$.

2. Ohta $\mathrm{Y}$, Nozawa $\mathrm{H}$, Tanaka $\mathrm{Y}$, Oda $\mathrm{M}$, Watanabe $\mathrm{Y}$. Increased vascular endothelial growth factor and vascular endothelial growth factor-c and decreased nm 23 expression associated with microdissemination in the lymph node in stage I non-small cell lung cancer. J Thorac Cardiovasc Surg. 2000;119:804-13.

3. Ohta Y, Endo Y, Tanaka M, et al. Significance of vascular endothelial growth factor messenger RNA expression in primary lung cancer. Clin Cancer Res. 1996;2:1411-6.

4. Gray BN. Colorectal cancer: the natural history of disseminated disease: a review. Aust N Z J Surg. 1980;50:643-6.

5. Schulten MF, Heiskell CA, Shields TW, et al. The incidence of solitary pulmonary metastasis from carcinoma of the large intestine. Surg Gynecol Obstet. 1976;43:727-9.

6. Wilking N, Petrelli NJ, Herrera L, Regal AM, Mittelman A. Surgical resection of pulmonary metastasis from colorectal adenocarcinoma. Dis Colon Rectum. 1985;28:562-4.

7. Mansel JK, Zinsmeister AR, Pairolero PC, Jett JR. Pulmonary resection of metastatic colorectal adenocarcinoma. Chest. 1986;89: 109-12.

8. Brister SJ, Varennes BD, Gordon PH, Sheiner NM, Pym J. Contemporary operative management of pulmonary metastasis of colorectal origin. Dis Colon Rectum. 1988;31:786-92.

9. Goya T, Miyazwa N, Kondo H, et al. Surgical resection of pulmonary metastasis from colorectal cancer. Cancer. 1989;64:1418-21.

10. McAfee MK, Allen MS, Trastek VF, et al. Colorectal lung metastasis: results of surgical excision. Ann Thorac Surg. 1992;53:780-6. 
11. Yano T, Hara N, Ichinose Y, et al. Results of pulmonary resection of metastatic colorectal cancer and its application. J Thorac Cardiovasc Surg. 1993;106:875-9.

12. Inoue M, Kotake Y, Nakagawa K, Fujiwara K, Fukuhara K, Yasumitsu T. Surgery for pulmonary metastasis from colorectal carcinoma. Ann Thorac Surg. 2000;70:380-3.

13. Pfannschmidt J, Muley T, Hoffmann H, Dienemann H. Prognostic factors and survival after complete resection of pulmonary metastases from colorectal carcinoma: experiences in 167 patients. J Thorac Cardiovasc Surg. 2003;126:732-9.

14. Folkman J, Watson K, Ingber D, et al. Induction of angiogenesis during the transition from hyperplasia to neoplasia. Nature. 1989;339: 56-8.

15. Gabrilovich DI, Chen HL, Girgis KR, et al. Production of vascular endothelial growth factor by human tumors inhibits the functional maturation of dendritic cells. Nat Med. 1996;2:1096-103.

16. Stobe M, Rockwell P, Goldstein N, et al. Halting angiogenesis suppresses carcinoma cell invasion. Nat Med. 1997;3:1222-7.

17. Herold-Mende C, Steiner H, Addl T, et al. Expression and functional significance of vascular endothelial growth factor receptors in human tumor cells. Lab Invest. 1999;79:1573-82.

18. Arbiser JL, Larsson H, Claesson-Welsh L, et al. Overexpression of VEGF 121 in immortalized endothelial cells causes conversion to slowly growing angiosarcoma and high level expression of the VEGF receptors VEGFR-1 and VEGFR-2 in vivo. Am J Pathol. 2000;156: 1469-76.

19. Baek JH, Jang J, Kang C, et al. Hypoxia-induced VEGF enhances tumor survivability via suppression of serum deprivation-induced apoptosis. Oncogene. 2000;19:4621-31.

20. Bruns CJ, Liu W, Davis DW, et al. Vascular endothelial growth factor is an in vivo survival factor for tumor endothelium in a murine model of colorectal carcinoma liver metastases. Cancer. 2000;89:488-99.

21. Tamura M, Ohta Y, Kajita T, et al. Plasma VEGF concentration can predict the tumor angiogenic capacity in non-small cell lung cancer. Oncol Rep. 2001;8:1097-102.

22. Werther K, Christensen IL, Nielsen HJ. Prognostic impact of matched preoperative plasma and serum VEGF in patients with primary colorectal carcinoma. Br J Cancer. 2002;86(3):417-23.

\section{ON THE MOVE?}

Don't miss a single issue of the journal! To ensure prompt service when you change your address, please photocopy and complete the form below.

Please send your change of address notification at least six weeks before your move to ensure continued service. We regret we cannot guarantee replacement of issues missed due to late notification.

\section{JOURNAL TITLE:}

Fill in the title of the journal here.

OLD ADDRESS:

Affix the address label from a recent issue of the journal here.

\section{NEW ADDRESS:}

Clearly print your new address here.

Name

Address

City/State/ZIP

\section{COPY AND MAIL THIS FORM TO:}

Elsevier Inc.

Subscription Customer Service

6277 Sea Harbor Dr

Orlando, FL 32887
OR FAX TO:

407-363-9661

OR E-mail:

elspcs@elsevier.com
OR PHONE:

800-654-2452

Outside the U.S., call

407-345-4000 